\title{
Article
}

\section{The impact of in-season national team soccer play on injury and player availability in a professional club}

Carling, C., McCall, A., Le Gall, F., and Dupont, G.

Available at http://clok.uclan.ac.uk/12334/

Carling, C. ORCID: 0000-0002-7456-3493, McCall, A., Le Gall, F., and Dupont, G. (2015) The impact of in-season national team soccer play on injury and player availability in a professional club. Journal of Sports Sciences, 33 (17). pp. 1751-1757. ISSN 0264-0414

It is advisable to refer to the publisher's version if you intend to cite from the work. http://dx.doi.org/10.1080/02640414.2015.1013051

For more information about UCLan's research in this area go to http://www.uclan.ac.uk/researchgroups/ and search for <name of research Group>.

For information about Research generally at UCLan please go to http://www.uclan.ac.uk/research/

All outputs in CLoK are protected by Intellectual Property Rights law, including Copyright law. Copyright, IPR and Moral Rights for the works on this site are retained by the individual authors and/or other copyright owners. Terms and conditions for use of this material are defined in the policies page.

\section{CLoK}

Central Lancashire online Knowledge www.clok.uclan.ac.uk

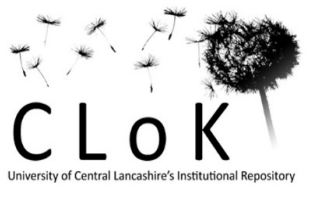


This is a pre-proof corrected manuscript, as accepted for publication, of an article published by

Taylore \& Francis in Journal of Sports Sciences on $9^{\text {th }}$ March 2015, available online:

http://www.tandfonline.com/doi/abs/10.1080/02640414.2015.1013051?url_ver=Z39.88-

2003\&rfr_id=ori:rid:crossref.org\&rfr_dat=cr_pub\%3dpubmed\#.Vbtks03bLcs

PLEASE REFER TO THE PUBLISHED VERSION FOR CITING PURPOSES

9 Title: The impact of in-season national team soccer play on injury and player availability in a

10 professional club

12 Authors: Christopher Carling ${ }^{1,2}$, Alan $\mathrm{McCall}^{2,3}$, Franck Le Gall ${ }^{2}$, Gregory Dupont ${ }^{2,3}$

\section{Institution:}

15 Institute of Coaching and Performance, University of Central Lancashire, UK

16 2LOSC Lille Métropole Football Club, Research and Development Department, Camphin-en-Pévèle,

17 France

$18{ }^{3}$ Univ Lille Nord de France, 59000 Lille, France - UDSL, EA 4488

19

20 Corresponding author:

21 Christopher Carling

22 Correspondance: LOSC Lille Metropole Football Club, Domain de Luchin, Camphin-en-Pévèle, 59780,

23 France.

24 Phone: 00.33.6.0392 1863

25 Fax: 00.33.1.48910793

26 Email: christopher.carling@gmail.com 
1 The impact of in-season national team soccer play on injury and player availability in a

2 professional club

3

4 Running head: Injury in national team soccer

5

6 Abstract

7 This study investigated the impact of in-season national team duty on injury rates and player availability

8 in a professional soccer club. Time-loss injuries and exposure time during club and national team duties

9 were recorded prospectively over 5-seasons (2009-2014). A time-loss injury was sustained by $37.7 \%$ of

10 squad members participating in national duty; all injuries occurring in match-play. The incidence (per

11 1000hours exposure) for national team player match-play injuries did not differ $(\mathrm{p}=0.608)$ to that for all

12 players in club competitions: 48.0 (95\% CI 20.9-75.5) vs. 41.9 (95\% CI 36.5-47.4), incidence rate

13 ratio=1.2 (CI: 0.8-2.4). The majority $(58 \%)$ of national team injuries resulted in a layoff $\leq 1$ week. Of all

14 working days lost to injury generally, 5.2\% were lost through injury on national duty. Injury incidence

15 in the week following national duty was comparable $(\mathrm{p}=0.818)$ in players participating or not: 7.8 (95\%

16 CI 3.6-12.0) vs. 7.1 (95\% CI: 4.6-9.6), incidence rate ratio=1.1 (CI: 0.7-2.7). While approximately forty

17 percent of participating players incurred a time-loss injury on national duty, no training injuries were

18 sustained and injuries made up a negligible part of overall club working days lost to injury. Following

19 duty, players had a similar injury risk to peers without national obligations.

20

21 Key terms: injuries, performance, football, match congestion, fatigue 


\section{Introduction}

Soccer injuries result from a complex interaction of multiple internal and external risk factors and player fatigue is perceived to be one of the most important factors related to injury risk in contemporary professional soccer (McCall et al, 2014). Indeed, clubs can play over 60 competitive matches per season with some players participating in up to 50 matches (Strudwick, 2012). In addition to their domestic League and Cup programmes and European competition, many professional players are regularly exposed to national team obligations both in-season (e.g., national team tournament qualification and friendly matches) and post-season (e.g., FIFA World Cup, UEFA European

9 Championships). In a one-season study of injury in European professional soccer, a total of 148 (56\%)

10 out of 266 players were exposed to some form of national team play on at least one occasion (Waldén,

11 Hägglund \& Ekstrand, 2005). While injury rates in post-season national team soccer tournaments are

12 generally higher in comparison to those reported at professional club standards (Dvorak, Junge, Derman

13 \& Schwellnus, 2011), little is known about injury rates and characteristics during in-season national

14 team training sessions or qualification and friendly matches and their subsequent impact on player availability. Similarly, to our knowledge, no information is available on the proportion of players who actually sustain an injury while on in-season national duty (training and match-play), the characteristics of injuries incurred, or the subsequent effect of these injuries on availability for future training sessions and competition in their club.

In-season national team matches are often closely preceded and followed by club matches. These intensive in-season competitive schedules frequently lead to periods of match congestion thereby requiring some players to play 2 matches per week consecutively over several weeks. Research in a Champions League team (Dupont et al., 2010) reported injury rates over 6-times higher when players participated in 2 club matches per week compared to only 1 match per week (25.6 vs. 4.1 per 1000 hours exposure). A study by Bengtsson and colleagues (2013) also demonstrated a strong association between muscle injury rates and the recovery time available between successive matches (according to the number of days) in 27 professional European clubs. In contrast, no significant difference was reported in the incidence of injury in match (27.2 vs. 33.8 per 1000 hours) or training sessions $(4.1 \mathrm{v} 6.2$ per 1000 hours) in players exposed or not to national duty over the course of a competitive season despite the national team players having played significantly more matches (42 vs. 28) (Waldén et al, 2005). Up to now, no study has investigated the potential effect of competitive schedules prior to national team duties in which players eventually sustained an injury or national team participation on injury rates during club training sessions and match-play immediately following duty. This information could eventually aid medical and coaching practitioners in making informed judgements on player rotation and recovery strategies around national team duties.

The aims of this study were to document injury rates during in-season national team duties and investigate the effects of duty on subsequent injury risk and player availability in a professional soccer club. 


\section{Methods}

2 In this prospective observational study, injuries in male professional soccer players belonging to the

3 first-team squad of a French Ligue 1 Club (highest competitive standard in France) sustained on both 4 national team soccer duty and in club competitions were investigated. While all data arose as a 5 condition of employment in which players were routinely monitored over the course of the competitive season (Winter \& Maughan, 2009), approval for the study from the present club and ethics committee clearance from the 'Comité de Protection des Personnes Nord Ouest IV' (France) were obtained.

Data were prospectively collected in a cumulated total of 130 players (59 individual players)

9 who participated in one or more seasons over a five-season period (2009-10, 2010-11, 2011-12, 2012-

1013 and 2013-14). A cumulated total of 58 players (44.6\%) out of the 130 participated in national duties

11 in one or more seasons over the five-season period. The cumulated total of 58 players included 30

12 individual players of which 17 (53.3\%) belonged to European, 12 to African (43.3\%) and 1 (3.3\%) to

13 South American national teams respectively. Altogether, 7 European, 6 African and 1 South American

14 teams were individually represented.

15 Individual exposure time to official club competitions (domestic league and cups, and European

16 Competition), pre-season friendly matches and training sessions was recorded for each individual player

17 belonging to the first-team squad by the club's sports scientist. Individual exposure time to in-season

18 national team match-play (including tournament qualification and friendly matches) was also recorded

19 for each player. Due to the non-presence of club medical and sports science staff, player exposure time

20 to training on national duty was estimated. After consultation with the participating national team

21 players, an average of 1.0 hours duration per training session was used to calculate training exposure 22 time.

23 Over the 5-season period, injuries sustained in club training and match-play were prospectively diagnosed and documented by the same sports physician. Injuries incurred during national duties were also diagnosed and documented on the player's return to the club. Essentially, diagnosis involved routine clinical assessment of players by the physician at the time of presentation. Where necessary, further examinations were ordered (e.g., sonography or magnetic resonance imaging) at the discretion of the physician to assist with diagnosis.

The definitions of injury, injury severity and recurrent injuries were based on those 30 recommended by International Soccer Injury Consensus Groups (Fuller et al., 2006; Hagglund, Walden,

31 Bahr \& Ekstrand, 2005). Injury: time-loss injury resulting from playing soccer and leading to a player being unable to fully participate in future training or match play independent of whether a training session actually took place on the day following injury or the player was selected to play in the next match. The incidence of injury was reported as the number of injuries per 1000 player-hours exposure to play. The severity of the injury (layoff time) was determined according to the number of days the player was absent from and unable to take full part in training or competition: minimal=1-3 days, mild $=4-7$ days, moderate $=8-28$ days and severe $=>28$ days. All injuries were followed until the final day 
of rehabilitation. The player was considered injured until the club physician permitted full participation in collective training and availability for match selection. A recurrent injury (reinjury) was described as an injury of the same type and at the same site as an index injury and that occurred within 2 months after a player's return to full participation from the index injury. The cause of injuries was obtained using post-match visualisation of the match video when available or alternatively via direct questioning by the club physician of the player on the latter's return to the club.

All statistical analyses were conducted using SPSS for Windows Version 14.0 (SPSS Inc.,

8 Chicago, IL, USA). Standard statistical procedures were used to calculate frequencies, means, 9 proportions (\%), standard deviations and ranges. Injury incidences (presented as injuries per 1000hours 10 play) and incidence rate ratios are both presented with $95 \%$ confidence intervals using respective 11 formulae presented in Dvorak et al (2011) and Knowles, Marshall \& Guskiewicz, (2006). After 12 normality of the data was tested, an unpaired t-test was used to compare injury incidences observed in 13 national teams and at club level. A p-value $<0.05$ was considered statistically significant. The $G^{*}$ Power 143 (Faul, Erdfelder, Lang et al. 2007) software was used to determine statistical power $(1-\beta>0.80$ was considered large).

\section{Results}

18 Players participated either fully or partly in a total of 206 national team matches over the 5-year period. 19 This resulted in a total participation time of 250.1 match hours of which 182.1 hours were spent in 20 tournament qualifying matches and 68.0 hours in friendly matches.

Of the 30 individual squad members participating in national duty at some time over the 5season period, 11 individual players (37.7\%) sustained an injury resulting in time loss from play. Altogether, 372 time-loss injuries (231 in match-play \& 141 in training) were reported over the 5seasons with a total of 12 injuries sustained in national team match-play accounting for $3.2 \%$ of all injuries sustained. No time-loss injuries were sustained in national team training sessions (estimated exposure time: 679 hours). Of the 12 injuries, 3 were reported in friendly matches and 9 in qualifying matches, $8(66.7 \%)$ were diagnosed as muscle strains and $3(25.0 \%)$ as sprains respectively, $8(66.7 \%)$ were sustained to the players dominant side, $10(83.3 \%)$ were as a result of non-contact trauma and 2 were considered reoccurrences (16.7\%) (Table 1). The upper leg was the most common injury location

30 (5 or $41.7 \%$ of which 3 affected the hamstrings and 2 the quadriceps muscles). In the week prior to the

3112 injury occurrences on national team duty, the injured and non-injured national team players had both played an identical mean number (and standard deviation) of $0.9 \pm 0.6$ matches.

The incidence of injuries incurred in national team training was 0.0 per 1000 hours play while at club level this was 3.0 (CI 2.8-3.3). The incidences of match injury occurring in national team soccer compared to that in all players in club match-play were 48.0 (CI 20.9-75.5) and 41.9 (CI: 36.5-47.4) respectively: incidence rate ratio of 1.2 (CI: 0.8-2.4). The t-test reported no significant difference 
between these incidences $(\mathrm{p}=0.608)$ while statistical power $(1-\beta)$ was 0.10 . The respective incidences of injury in tournament qualifying and friendly matches were 49.4 (CI 32.9-65.9) and 44.2 (CI 18.7-69.6).

A total of 288 days layoff time due to injuries sustained in national team match-play was observed. The mean length of the injuries occurring in national team and club match-play respectively was $24.0 \pm 46.2$ days (range 2-169 days, $16.7 \%$ were classed as minimal, $41.7 \%$ as mild, $33.3 \%$ as moderate and $8.3 \%$ as severe) and $8.9 \pm 15.0$ days (range 1-94 days, $46.6 \%$ were classed as minimal, $24.7 \%$ as mild, $22.4 \%$ as moderate and $6.4 \%$ as severe). Of the 12 injuries, $10(83.3 \%)$ forced the player to miss the following club match. Of the total of 2856 training sessions, 4290 training hours, 638 matches and 3494 working days (training and matches combined) missed through injury generally, 182 sessions (6.4\%), 281 hours (6.6\%), 36 matches (5.6\%) and $182(5.2 \%)$ working days respectively were missed directly through injuries sustained on national team duty. When the 182 club training sessions and 281 training hours missed through injury sustained on national duty were coupled with the 1075 training sessions and 1634 hours of club training missed while away on duty, this led to player absence from a total of $4.2 \%$ of all club training sessions and $4.3 \%$ of training hours.

In the week immediately following national team duty, players participated in $70.1 \%$ of their club's matches (115 out of 164 matches). Players completed at least 75 -minutes in $67.0 \%$ ( 77 out of 115 matches) and 90-minutes play in 55.7\% (64 out of 115 matches) of matches respectively. Of the $29.9 \%$ of matches (49/164) in which players did not compete, 14.3\% (7 out of 49) were directly missed through an injury sustained on national team duty. Altogether, 13 injuries (incidence per 1000hours play=7.8, CI 3.6-12.0) were sustained in match-play and training combined in the week directly following national duty compared to an incidence of 7.1 (CI: 4.6-9.6) in the players who were not selected for their national team: incidence rate ratio of 1.1 (CI: 0.7-2.7). The t-test reported no significant difference between these incidences $(\mathrm{p}=0.818)$ while statistical power $(1-\beta)$ was 0.08 . Of the 13 injuries sustained, $5(38.5 \%)$ were diagnosed as muscle strains, $3(23.1 \%)$ as contusions and 2 $(15.4 \%)$ as tendinopathies while $61.5 \%$ were due to non-contact trauma. The mean layoff time per injury incurred directly after national duty equalled 13.9 \pm 25.4 days (range 1-94 days) with the majority (76.9\%) resulting in a layoff of one week or less. These injuries subsequently forced players to miss a total of 136 training sessions (206 hours), 34 matches and 163 working days.

\section{Discussion}

31 In epidemiological studies conducted at the highest standards of soccer, it is important to account for 32 the impact of exposure to national team duty and injuries subsequently incurred (Waldén et al., 2005). 33 The aim of the present study was to analyse the impact of national team duty on injury and player availability in players belonging to a professional soccer club over a 5-season period. Main findings were that approximately $40 \%$ of players participating in national team match-play sustained an injury accounting for $\sim 3 \%$ of all the club's injuries reported over the 5-seasons while no injuries were reported during national team training sessions. While the incidence of match-play injury was $\sim 13 \%$ higher in 
national versus club competitions, incidence rate ratios with corresponding confidence intervals and inferential statistical testing indicated no significant difference between rates. The majority of injuries sustained in national team matches resulted in absence from soccer for one week and or less. Of the total number of club working days (training and matches combined) missed through injury generally, $\sim 5 \%$ were directly missed through injuries incurred in national team competition. The injury incidences in play over the week immediately following national team participation did not differ between players who had or had not participated in national team duty.

In the present study, $\sim 3 \%$ of all injuries in the club's players sustained over 5-seasons occurred 9 in national team circumstances, a figure similar to the $4 \%$ reported in 11 top European soccer clubs 10 (Waldén et al., 2005). Altogether, $38 \%$ of players sustained an injury during exposure to national duty 11 which compares to $29 \%$ in a population of 65 players monitored prior to and during the 2002 World 12 Cup (Ekstrand, Waldén \& Hägglund, 2004). Positively, no injuries were reported during national team 13 training sessions in contrast to an incidence of 3.0 per 1000 hours (CI 2.5-3.5) in club training. It must 14 be acknowledged though that some slight injuries ( 0 days layoff) could have occurred in training and might not have been reported. An explanation already put forward elsewhere for this positive finding for training injury might be differences in the type and/or intensity of training sessions performed on national team duty. As the preparation time available for national friendly and qualification matches is 18 habitually short, then it might be speculated that sessions were less intensive, more recovery-based and tactical in nature (Hägglund, Waldén \& Ekstrand, 2009; Waldén, Hägglund \& Ekstrand, 2007). In future studies, detailed logging and comparison of training activities and workloads in both club and national contexts would be useful to confirm or refute this suggestion.

Results showed that the incidence of injury occurring in national team soccer match-play did not differ statistically compared to that observed during club competitions (48.2 versus 41.9 injuries per 1000 hours, $\mathrm{p}=0.608$ ). However, this difference represents a non-negligible $13 \%$ difference and could nevertheless be interpreted as partly confirming the trend for general higher risk of injury in national team tournament match-play in comparison to professional club soccer (Dvorak et al., 2011; Ekstrand, Hägglund \& Waldén, 2011). Whilst to our knowledge no comparative data exist on injury rates specific to in-season national team qualification and friendly matches as presented here, the present incidence is within the range previously reported for post-season national team tournaments over the last decade or so: 2002 FIFA World Cup=50.7 (Junge, Dvorak \& Graf-Baumann, 2004), 2006 FIFA World Cup=45.9

31 (Dvorak, Jungen, Grimmn \& Kirkendall, 2007), FIFA 2010 World Cup=40.1 (Dvorak et al., 2011),

32 FIFA 2009 Confederations Cup=60.1 (Theron, Schwellnus, Derman \& Dvorak, 2013), EURO 2004=36.0 (Waldén et al., 2007), and EURO 2008=41.6 (Hägglund et al., 2009). Additional largerscale research in other professional clubs to quantify and compare injury rates during in-season national team duty and identify the extent of the risk internationally is warranted.

The high injury rates observed above for post-season national team tournaments have been

37 linked to pressure and associated mental stress (Hägglund et al., 2009), as well as accumulated fatigue 
and the density of matches played prior to the competition (Ekstrand et al., 2004). Match congestion at club level ( 2 versus 1 game per week) has also been associated with a six-fold increased risk of injury (Dupont et al., 2010). However, analyses of the 7-day period prior to the in-season national team matches in which the 12 injuries were incurred showed that both the national team players who subsequently sustained an injury and those who did not, had, on average, played a single game. Thus, it would seem that exposure time to club match-play prior to national team duty was not linked to the injuries sustained in players participating in national team play.

We also investigated how involvement with national teams affected injury in participating players over the following week back in their club environment in comparison to peers not selected for duty. Similar rates of injury were reported (incidence per 1000 hours play: 7.8 vs. $7.1, \mathrm{p}=0.818$ ) suggesting that involvement in national teams had no effect on subsequent injury risk at club level. A reasonable explanation for this finding might be management of player participation in the following club game which tended to take place 3-4 days afterwards. Approximately $70 \%$ of the national team players participated in the club's next match but only about half of these completed the full 90-minutes of match-play. Out of the club's national team players habitually considered by the coaching staff as 'first-team starters', $\sim 82 \%$ participated in the club's next match following national duty but only $54 \%$ completed 90-minutes. Combined, these results imply that the present club coaching staff took into account prior national duties when selecting and especially substituting players potentially with the aim of reducing the recognised higher injury risk linked to match congestion (Bengtsson et al., 2013; Dupont et al., 2010) and towards the latter end of play (Ekstrand et al., 2011; Hawkins et al, 2001). Future work using interviews with coaching staff to determine their criteria for selection or not of players who had recent involvement at national team level is warranted.

The impact of an injury on a club can be considered in relation to its severity and the number of potential competitive matches missed (Hawkins et al., 2001). Here, the impact of injuries sustained during national duty in relation to all injuries sustained during club obligations on the frequency of training sessions ( $\sim 6 \%)$ and hours $(\sim 7 \%)$, matches ( $\sim 6 \%)$ and working days $(\sim 5 \%)$ subsequently missed can be considered minimal. In contrast, an average of 3.0 matches was subsequently missed per national team injury with $\sim 83 \%$ of the injuries leading to absence in at least one club match. In national team versus club competition, $\sim 42 \%$ of injuries were classed as moderate/severe ( $\geq 8$ days) compared to $229 \%$. This suggests that when an injury occurred in national team competition, its severity and subsequent effect on player availability was potentially greater. However, player absence and injury severity must be interpreted with in the context of the low number of injury cases occurring during national duty along with the presence of an important injury outlier. Indeed, when the outlier (169 days layoff time for a tendon injury) is removed from the analysis, the mean length of the injuries occurring in national team versus club match-play was relatively similar: 10.8 vs. 8.9 days.

Finally, of the 12 injuries reported in national team competition, $\sim 80 \%$ were sustained in a noncontact situation and two-thirds ( $67 \%)$ were muscle strains versus $\sim 50 \%$ and $\sim 40 \%$ in club match-play 
respectively. It is difficult to formulate solid explanations for these discrepancies in injury patterns mainly again due to the small number of reported injuries and again additional research is necessary to verify this trend.

In light of the present findings, we feel that future research into the potential 'knock-on' effects of participation in tournaments such as the World Cup and Continental Championships on injury risk in professional soccer players over the course of the following season is warranted. Previous research has shown that forty-one per cent of injuries sustained in the European Championships 2006 to 2008 resulted in absence after the tournament, with an average of nearly four weeks subsequently spent in

9 rehabilitation (Hägglund et al., 2009). Research to examine whether players who participate in a large 10 number of in-season qualification and friendly matches followed by a post-season tournament are 11 consequently subjected to greater injury risk in the following season is warranted. We also suggest that 12 analysis of the potential effects of travel (e.g, duration and distance, time zones) especially in players 13 travelling to different continents on subsequent injury risk during exposure to national team play and on 14 return to their clubs would be pertinent. Finally, a multifactorial model of sports injury etiology (Bahr $15 \&$ Homes, 2003) would help to explore the potential interrelationships between internal risk factors and their contribution to injury rates and patterns in national team players.

A limitation acknowledged at the outset of this study was that only one soccer club was 18 investigated and the patterns observed are a reflection of this particular cohort. Sample size influences 19 the power to detect real and significant effects and similar investigations involving a larger sample of 20 professional clubs internationally to increase statistical power are necessary to verify the present 21 findings. Indeed, power for statistical comparisons reported here was $\leq 0.10$. Despite prospective data 22 collection from over 200 national team matches played over a 5-season period, only 12 injury cases 23 were reported in 11 individual players which is insufficient to detect moderate to strong associations 24 (20-50 injury cases) and small to moderate associations ( 200 injured subjects) (Bahr \& Holme, 2003). 25 However, despite these limitations, this study has merit in that it is the first to investigate the impact of 26 in-season national team duty on injury and player availability at professional soccer club level. In 27 addition, the strength of this investigation was its five-season span and prospective nature and 28 methodology the latter respecting internationally recommended injury recording systems (Fuller et al., 29 2006; Hagglund et al., 2005) thereby allowing these results to be compared with future research 30 findings.

\section{Conclusion}

33 In conclusion, this study showed that while in the region of $40 \%$ of participating players sustained an 34 injury on national team duty, no injuries were sustained in national team training sessions. National 35 team match-play injury rates did not differ statistically compared to that in players in club competitions 36 making up a negligible part of all injuries incurred in the club over a 5-season period. Following 
1 national duty, injury incidence in participating players was not greater than in peers who had no 2 national obligations. 


\section{References}

2 Bahr, R., \& Holme, I. (2003). Risk factors for sports injuries-a methodological approach. British

3 Journal of Sports Medicine, 37, 384-392.

4 Bengtsson, H., Ekstrand, J., \& Hagglund, M. (2013). Muscle injury rates in professional soccer

5 increases with fixture congestion: an 11-year follow-up of the UEFA Champions League injury study.

6 British Journal of Sports Medicine, 47, 743-747.

7 Dupont, G., Nedelec, M., McCall, A., McCormack, D., Berthoin, S., \& Wisløff, U. (2010). Effect of 2

8 soccer matches in a week on physical performance and injury rate. American Journal of Sports

9 Medicine, 38, 1752-1758.

10 Dvorak, J., Junge, A., Derman, W., \& Schwellnus, M. (2011). Injuries and illnesses of soccer players

11 during the 2010 FIFA World Cup. British Journal of Sports Medicine, 45, 626-630.

12 Dvorak, J., Jungen A., Grimmn K., \& Kirkendall, D. (2007). Medical report from the 2006 FIFA World

13 Cup Germany. British Journal of Sports Medicine, 41, 57-81.

141. Ekstrand, J., Waldén, M., \& Hägglund, M. (2004). A congested soccer calendar and the wellbeing of

15 players: Correlation between match exposure of European soccerers before the World Cup 2002 and

16 their injuries and performances during that World Cup. British Journal of Sports Medicine, 38, 493-

17497.

18 Ekstrand, J., Hägglund, M., \& Waldén, M. (2011). Injury incidence and injury patterns in professional 19 soccer: the UEFA injury study. British Journal of Sports Medicine, 45, 553-558.

20 Faul, F., Erdfelder, E., Lang, A., \& Buchner, A. (2007). G*Power 3: a flexible statistical power analysis 21 program for the social, behavioral, and biomedical sciences. Behavioral Research Methods, 39, 17522191.

23 Fuller, C.W., Ekstrand, J, Junge, A., Andersen, T.E., Bahr, R., Dvorak, J., Hägglund, M., McCrory, P., $24 \&$ Meeuwisse, W.H. (2006). Consensus statement on injury definitions and data collection procedures 25 in studies of soccer (soccer) injuries. Clinical Journal of Sports Medicine, 16, 97-106.

26 Hagglund, M., Walden, M., Bahr, R., \& Ekstrand, J. (2005). Methods for epidemiological study of 27 injuries to professional soccer players: developing the UEFA model. British Journal of Sports 28 Medicine, 39, 340-346.

29 Hägglund, M., Waldén, M., \& Ekstrand, J. (2009). UEFA injury study-an injury audit of European 30 Championships 2006 to 2008. British Journal of Sports Medicine, 43, 483-489.

31 Hawkins, R.D., Hulse, M.A., Wilkinson, C., Hodson, A., Andersen, T., \& Bahr, R. (2001). The 32 association soccer medical research programme: an audit of injuries in professional soccer. British 33 Journal of Sports Medicine, 35, 43-47.

34 Junge, A., Dvorak, J., \& Graf-Baumann T. Soccer injuries during the World Cup 2002. (2004). 35 American Journal of Sports Medicine, 32(1 Suppl), 23S-7S.

361. Knowles, S.B, Marshall, S.W., \& Guskiewicz, K.M. (2006). Issues in estimating risks and rates in 37 sports injury research. Journal of Athletic Training, 41, 207-215. 
12. McCall, A., Carling, C., Nedelec, M., Davison M., Le Gall, F., Berthoin, S., \& Dupont, G. (2014) Risk 2 factors, testing and preventative strategies for non-contact injuries in professional football: current 3 perceptions and practices of 44 teams from various premier leagues. British Journal of Sports Medicine, $4 \quad 48,1352-1357$.

5 Strudwick, T. (2012). Contemporary issues in the physical preparation of elite players. In: M. Williams 6 ed. Science \& Soccer III. London. Routledge, 335-356.

7 Theron, N., Schwellnus, M., Derman, W., \& Dvorak, J. (2013). Illness and injuries in elite soccer 8 players--a prospective cohort study during the FIFA Confederations Cup 2009. Clinical Journal of 9 Sports Medicine, 23, 379-383.

10 Waldén, M., Hägglund, M., \& Ekstrand, J. (2005). UEFA Champions League study: a prospective study 11 of injuries in professional soccer during the 2001-2002 season. British Journal of Sports Medicine, 39, $12542-546$.

13 Waldén, M., Hägglund, M., \& Ekstrand, J. (2007). Soccer injuries during European Championships 14 2004-2005. Knee Surgery, Sports Traumatology, Arthroscopy, 15, 1155-1156.

15 Winter, E.M., \& Maughan, R.J. (2009). Requirements for ethics approvals. Journal of Sports Sciences, $16 \quad 27,985$.

17 
Table 1 Description of 12 injuries sustained in professional soccer players on international duty over a 5-season period

\begin{tabular}{|c|c|c|c|c|c|c|c|c|c|c|c|c|}
\hline Competitive & Playing & Layoff & & sessions absent & $\mathrm{N}^{\circ}$ matches & Working days & Injury & haracteristics & & & & \\
\hline season & position & time (days) & $\mathrm{N}^{\circ}$ & Hours & absent & absent & Type & Location & Dominant side & Reinjury & Contact & Cause \\
\hline $2009-10$ & Midfielder & 13 & 8 & 14 & 1 & 7 & Sprain & Toe & Yes & No & Yes & Tackle \\
\hline $2009-10$ & Forward & 6 & 3 & 5 & 1 & 4 & Strain & Pelvis & Yes & No & Yes & Collision \\
\hline $2010-11$ & Forward & 2 & 2 & 3 & 0 & 2 & Strain & Hamstring & No & No & No & Unknown \\
\hline 2010-11 & Defender & 2 & 2 & 3 & 1 & 2 & Strain & Neck & Yes & No & No & Collision \\
\hline 2010-11 & Forward & 14 & 9 & 14 & 1 & 10 & Strain & Hamstring & Yes & No & No & Kicking ball \\
\hline 2011-12 & Defender & 8 & 5 & 8 & 1 & 6 & Strain & Quadriceps & Yes & No & No & Unknown \\
\hline 2012-13 & Midfielder & 17 & 5 & 8 & 1 & 6 & Sprain & Knee & Yes & No & No & Tackled \\
\hline $2012-13$ & Defender & 25 & 13 & 21 & 5 & 18 & Strain & Foot & No & No & No & $\begin{array}{l}\text { Change in } \\
\text { direction }\end{array}$ \\
\hline 2012-13 & Forward & 7 & 9 & 14 & 1 & 9 & Strain & Hamstring & No & Yes & No & Acceleration \\
\hline $2012-13$ & Midfielder & 20 & 14 & 23 & 5 & 19 & Sprain & Ankle & Yes & No & Yes & Collision \\
\hline $2012-13$ & Forward & 169 & 108 & 162 & 19 & 95 & Tendinopathy & Ankle & Yes & Yes & No & $\begin{array}{l}\text { Change in } \\
\text { direction }\end{array}$ \\
\hline 2013-14 & Forward & 5 & 4 & 6 & 0 & 4 & Strain & Quadriceps & No & No & No & $\begin{array}{l}\text { Change in } \\
\text { direction }\end{array}$ \\
\hline
\end{tabular}

